Special Issue: Biological effects of space radiation -Part I-

\section{Proteomic Approach for Biomarker Discovery in Radioadaptive Responses -Age-Dependent Variations of Cell Response to Low-Dose Radiation-}

\section{Yuri Miura}

Research Team for Functional Genomics, Tokyo Metropolitan Institute of Gerontology, 35-2 Sakaecho, Itabashi-ku, Tokyo 173-0015, Japan

\begin{abstract}
Organisms are exposed to various low-dose radiation in space. Ionizing radiation causes diverse damage, carcinogenesis, and cell death; however, low-dose radiation is reported to induce adaptive responses, different from high dose. The radioadaptive response caused by low-dose radiation is an important factor in the adaptation to life in space; therefore, we tried to identify a biomarker protein as an indicator of radioadaptive response, and to develop an index of adaptability to a stay in space. In the present review, the radioadaptive response in cultured astrocytes and the effects of aging will be described, in addition to the proteomics approach for the variation of protein expression and phosphorylation involved in the radioadaptive response. (C2009 Jpn. Soc. Biol. Sci. Space; Article ID: 092301003
\end{abstract}

\section{Introduction}

The healthcare of astronauts is most important in long-term life in space. Organisms in space are exposed to various low-dose radiation, such as high-energy particle rays, $\mathrm{y}$-ray, and $\mathrm{x}$-ray; therefore, it is necessary to estimate the radiation effects on the health of astronauts, especially low-dose effects. Low-dose ionizing radiation is known to induce hormesis and an adaptive response as a stimulant. Olivieri et al. first reported the radioadaptive response in mammalian cells (Olivieri et al., 1984). Since then, many reports have indicated that the adaptive response can be widely observed by various indexes, for example, chromosomal aberration, cell survival, apoptosis, and cell growth (Marples and Joiner, 1993; Sasaki, 1995; Korystov et al., 1996; Venkat et al., 1996; Wouters et al. 1996; Filippovich et al., 1998; Suzuki et al., 1998; Park et al., 1999). Since radiation is known to produce reactive oxygen species (ROS) and to cause

Received: April 15, 2009; Accepted: May 25, 2009

Review Article

Tel.: +81-3-3964-3241; Fax: +81-3-3579-4776;

E-mail:miura@tmig.or.jp oxidative stress in various biological systems, ROS and reactive nitrogen species (RNS), which are generated by conditioning dose, are involved in radioadaptive response (lyer and Lehnert, 2002; Matsumoto et al., 2004; de Toledo et al., 2006; Matsumoto et al., 2007a; Matsumoto et al., 2007b; Takahashi et al., 2008). Low-dose conditioning irradiation causes a regulatory imbalance in redox homeostasis and triggers redox-sensitive signaling pathways, resulting in the induction of biological defense systems, including DNA repair and antioxidant defense systems, and the acquirement of resistance to subsequent high-dose challenging irradiation. Although subsequent challenging irradiation gives rise to various types of cellular damages, the induction of radioresistance by conditioning dose reduces genotoxic or epigenotoxic damage due to challenging irradiation (Miura, 2004; Tapio and Jacob, 2007). Although the detailed molecular mechanisms or signaling pathway of the adaptive response remain unclear, the discovery of biomarkers of adaptive response would be a beneficial indicator of adaptation to life in space and to estimate the aptitude of astronauts.

Proteomic analysis offers great potential for studies on cellular protein alterations in various diseases (Hiratsuka et al., 2003; Oh-Ishi et al., 2003), aging (Toda et al., 1998; Schoneich 2003; Sato et al. 2006), oxidative stress (Mitsumoto et al., 2001) and radiation effects (Szkanderova et al., 2003; Berglund et al., 2009). Radiation effects on protein profiles have been generally studied on the high-dose effects to explore clinical biomarkers of radiotherapy (Menard et al., 2006) and the factors responsible for radiation resistance (Wang et al., 2005), and to elucidate radiation injury caused by depleted uranium (Malard et al., 2005). We focused on low-dose effects and analyzed the variation of protein expression and phosphorylation involved in the radioadaptive response using proteomics (Miura et al., 2007).

Furthermore, considering that the age of astronauts ranges widely, and that the elderly might travel to space in the future, it is necessary to investigate aging effects on radioadaptive response. This review focuses on the radioadaptive response in astrocytes cultured from various aged rats, and the proteomic approach for biomarker discovery in radioadaptive responses.

\section{Radioadaptive Responses to Low-Dose Irradiation in Glial Cell Growth and Aging Effects}

The central nervous system consists of neurons and glial cells, including astrocytes, microglias, and oligodendrocytes. Because of the high metabolic demand for oxygen and many oxidizable polyunsaturated fatty acids in membrane lipids, oxidative metabolism and the generation of reactive oxygen species (ROS) play a key role in the function of the central nervous system. Glial cells, especially astrocytes, are more resistant to oxidative stress than neurons (Bolanos et al., 1995; Hollensworth 


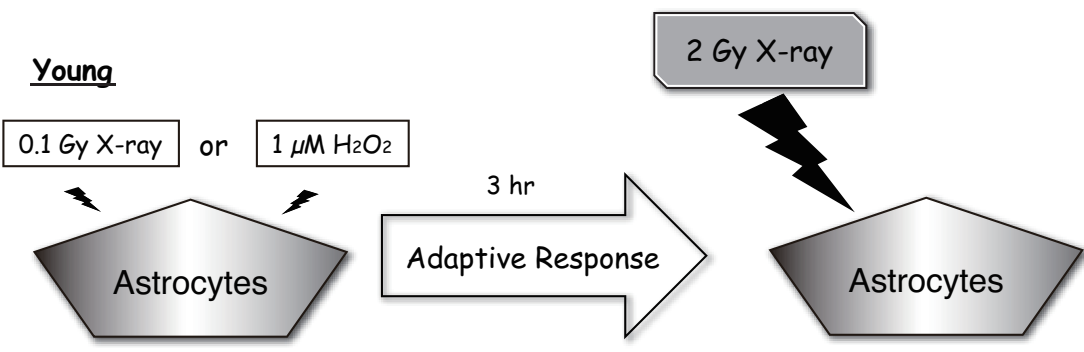

Adaptive Response was induced

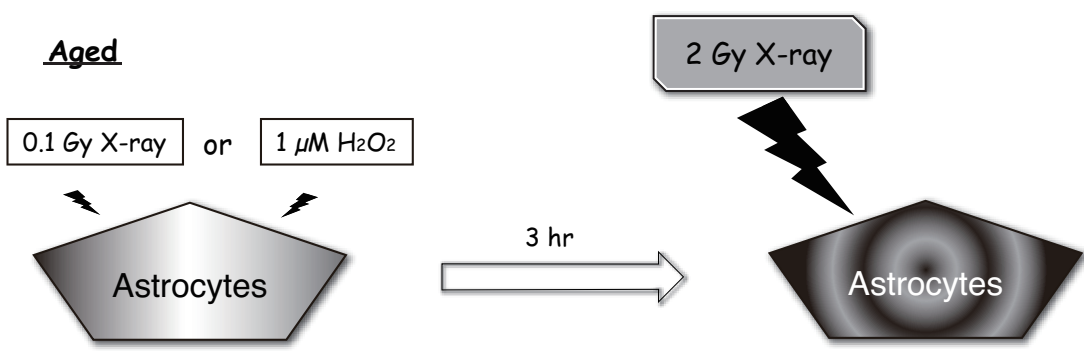

Adaptive Response was not induced

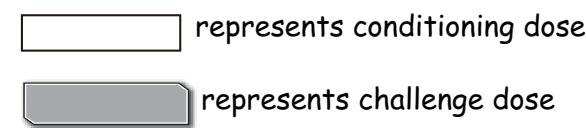

Fig. 1. Schematic illustration of adaptive response in rat astrocytes

et al., 2000) and support the survival of neurons by releasing various antioxidants and nutritional factors (Noel and Tofilon, 1998; Tanaka et al., 1999); therefore, astrocytes are thought to have mechanisms that respond to various oxidative stresses, including ionizing radiation. Thus, we examined the adaptive response to low-dose irradiation and hydrogen peroxide by observing the cell growth of astrocytes cultured from various aged rats (Miura et al., 2002; Miura, 2004). The conditioning dose was $0.1 \mathrm{~Gy} X$-ray or $1 \mu \mathrm{M} \mathrm{H}_{2} \mathrm{O}_{2}$, and the challenge dose was 2 Gy X-ray. In astrocytes from young rats (1 month old), pre-treatment with the conditioning dose prevented cell growth inhibition due to the challenge dose, suggesting that the conditioning dose induced adaptive response. On the other hand, in astrocytes from middle- (9 months old) and aged rats (24 months old), adaptive responses were not induced (Fig. 1). Furthermore, when the interval between the conditioning and challenge doses was $3 \mathrm{~h}$, an adaptive response was induced, while it was not induced with a $24 \mathrm{~h}$ interval, even in young rats' astrocytes.

To determine why the radiation adaptive response is suppressed with age, we tried to explore the potential proteins responsible for the radioadaptive response and performed proteomics analysis on the effects of lowdose irradiation in rat astrocytes. Furthermore, ionizing radiation is known to activate various signaling molecules (Schmidt-Ullrich et al., 2000), such as protein kinase C
(PKC) (Shimizu et al., 1999), mitogenactivated protein kinase (MAPK) (Shimizu et al., 1999), p53 (Wang, 2001; Takahashi, 2002), ataxia-telansiectasia mutated (ATM) (Nemethova et al., 1995) and DNA-dependent protein kinase (DNA-PK) (Miura et al., 2002; Takahashi et al., 2002), and these activations are mediated by phosphorylation; therefore, we examined the alteration of phosphoproteins due to low-dose irradiation using proteomics (Miura et al., 2007).

\section{Variation of Protein Expressions and Phosphoproteins Caused by Low-Dose Irradiation}

Low dose irradiation is known to change the expression and the posttranslational modifications such as phosphorylation of various proteins, for example, signaling molecules, molecular chaperones, and transcription factors (Mohan and Meltz, 1994; Suzuki et al., 2001; Matsumoto et al., 2007b; Takahashi et al., 2008; Ahmed et al., 2009). Although these proteins are considered to participate in radioadaptive response in any way, we tried to identify the cellular proteins responsible for radioadaptive response more comprehensive and widely, and analyzed by means of proteomics. Protein extraction and 2D-PAGE were performed as previously reported (Miura et al., 2005). Three cell groups ('Control', ' $3 \mathrm{~h}$ after irradiation' and '24 $\mathrm{h}$ after irradiation') irradiated at the same time were examined simultaneously from protein extraction to gel matching. The search for radiationresponsive protein spots and normalization of their relative abundance were performed using PDQuest software (Bio-Rad Laboratories) as described previously (Miura et al., 2005). When the abundance of spots on $2 \mathrm{D}$ gels of irradiated cells was $>2$-fold or $<1 / 2$-fold than control cells, we regarded the spots as radiationresponsive proteins. The relative abundance of radiationresponsive proteins spots was normalized against that of internal standard spots, which existed close to the spot and were expressed strongly and constantly. To analyze phosphorylated protein profiles, protein spots on the gel were stained with Pro- ${ }^{\circledR}$ Diamond phosphoprotein gel stain, a specific stain for phosphoproteins. In gel digestion of selected gel spots and peptide mass fingerprinting (PMF) were also performed as described previously (Miura et al., 2005). Tryptic peptides were analyzed using a MALDI-TOF mass spectrometer (AXIMA-CFR, Shimadzu Biotech) and/or MALDI-QIT-TOF mass spectrometer (AXIMA-QIT, Shimadzu Biotech). For protein identification, tryptic peptide mass data were sent to the Mascot search engine (Matrix Science, London, 
a

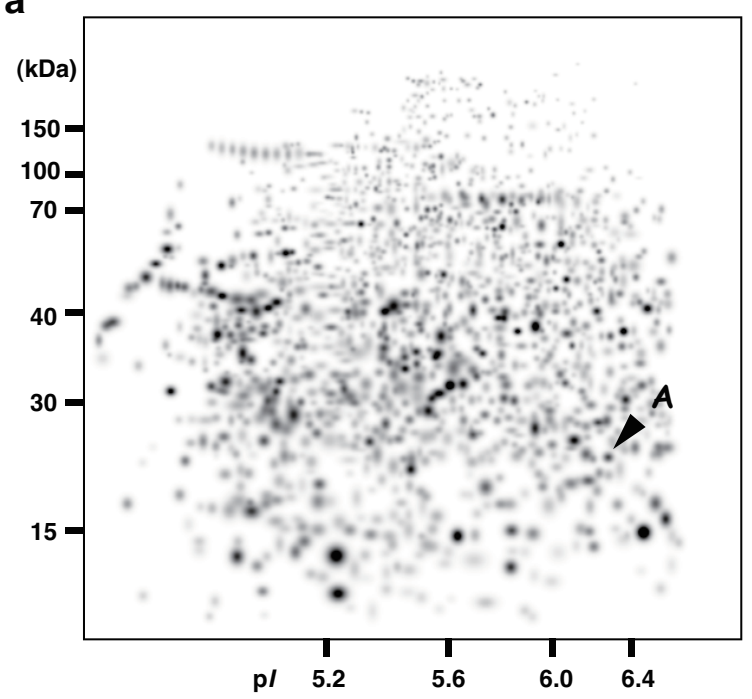

b

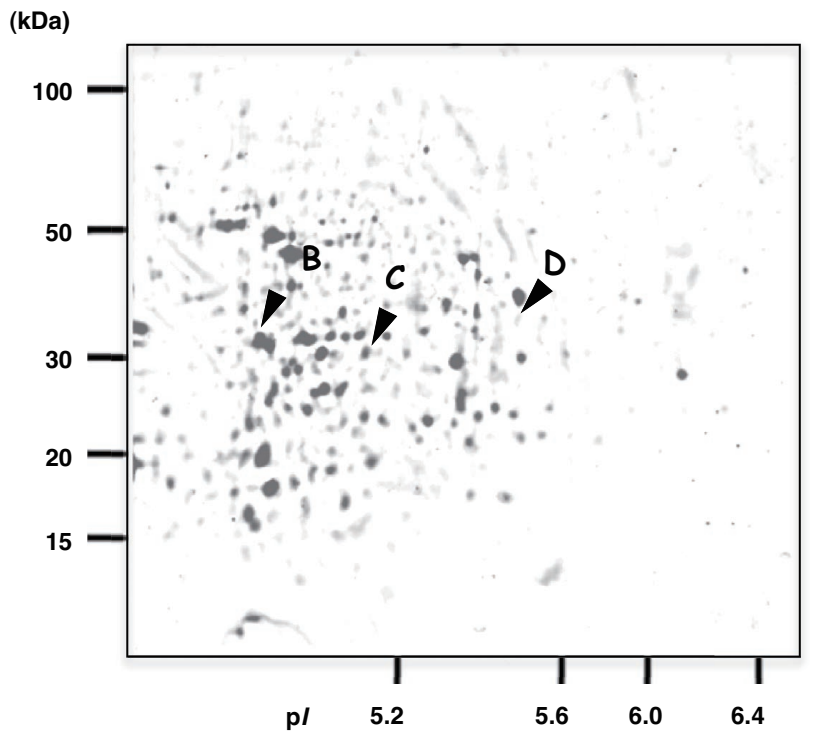

Fig. 2. Typical protein (a) and phosphoprotein (b) profiles of $2 \mathrm{D}$ PAGE for young rat astrocytes.

Vertical axes are designated as molecular mass (kDa) and horizontal axes as pl.

a. 2D gel was stained with silver. Spot A represents 0.1 Gy irradiation-responsive protein. It was identified as EF-2 fragment. b. $2 \mathrm{D}$ gel was stained with Pro- $\mathrm{Q}^{\circledR}$ Diamond phosphoprotein gel stain. Spot B-D represent 0.1 Gy irradiation-responsive phosphoproteins. Spot B, C, and D were identified as EF-1 $\beta$, $\beta$-actin, and $\beta$-actin, respectively.

UK available at: http://matrixscience.com/) as queries for searching the Swiss-Prot protein databases.

Figure 2 a shows a typical protein profile of rat astrocytes by 2D-PAGE. When comparing gels of nonirradiated cells (control) and 0.1 Gy-irradiated cells, spots that had changed $>2$-fold or $<1 / 2$-fold in abundance were sought. Spot A (Fig. 2a) was temporarily increased $3 \mathrm{~h}$ after 0.1 Gy irradiation. In order to identify protein spot A, tryptic peptides extracted from spot A were analyzed by MALDI-TOF MS/MS. Fragment ion masses obtained by MS/MS analysis were sent to the Mascot search engine as queries. The Mascot search score was 207 and four peptides were matched, concluding that spot $A$ was a fragment of elongation factor 2 (EF-2 fragment). Using Pro- ${ }^{\circledR}$ Diamond, which is a specific stain for phosphoproteins, radiation responsive phosphoproteins were examined, with the result that spot B-D (Fig. 2b) changed within $3 \mathrm{~h}$ after $0.1 \mathrm{~Gy}$ irradiation. Spot B and C decreased $3 \mathrm{~h}$ after 0.1 Gy irradiation, while spot $D$ was increased. To identify these proteins, tryptic peptides were analyzed by MALDI-TOF MS and database searches were performed using the Mascot search engine, concluding that spot $B, C$, and $D$ were elongation factor $1 \beta(E F-1 \beta), \beta$-actin, and $\beta$-actin, respectively. It was suggested that EF-1 $\beta$ was dephosphorylated, and that $\beta$-actin was dephosphorylated (spot C) and phosphorylated (spot D) 3h after 0.1 Gy irradiation.

\section{Aging Effects of Low-Dose Radiation- Responsive Proteins}

The adaptive response in the growth of rat astrocytes was suppressed with aging and was not observed in 24-month-old rat cells. Furthermore, when the interval between conditioning and challenge irradiation was $3 \mathrm{~h}$, an adaptive response was observed, while it did not occur with a 24-h interval, even in young rat cells (Miura, 2004), suggesting that any proteins responsible for the adaptive response are induced $3 \mathrm{~h}$ after $0.1 \mathrm{~Gy}$ irradiation only in astrocytes from young rats. Thus, in order to explore the proteins responsible for the radioadaptive response under the present conditions, we examined the effects of aging on protein expression and phosphorylation in astrocytes from young and aged rats. As a result, the temporary increase in the abundance of EF-2 fragment was not observed in astrocytes from aged rats, while phosphoproteins, EF- $1 \beta$ and $\beta$-actin, also varied by $0.1 \mathrm{~Gy}$ irradiation in astrocytes from aged rats, similarly to young rats. It is suggested that alteration of the EF-2 fragment corresponded to the occurrence of a radioadaptive response; therefore, the EF-2 fragment is a candidate biomarker responsible for the adaptive response in astrocytes induced by low-dose irradiation. EF-2 plays a role in the peptide elongation step of protein synthesis (Weissbach\&Ochoa 1976). If the EF-2 fragment (MW; ca. $21.5 \mathrm{kDa}$ ) is produced by the degradation of native EF-2 (MW; $97 \mathrm{kDa}$ ), protein synthesis should be temporarily inhibited by 0.1 Gy irradiation. We examined the effects of 0.1 Gy irradiation on native EF-2 expression in astrocytes from young and aged rats by Western blot and quantitative real-time RT-PCR, with the result that neither EF-2 protein nor mRNA were affected by 0.1 Gy irradiation in astrocytes from young and aged rats. This suggested that temporal up-regulation of the EF-2 fragment due to 0.1 Gy irradiation did not affect the abundance of native EF-2, that is, the function of protein 


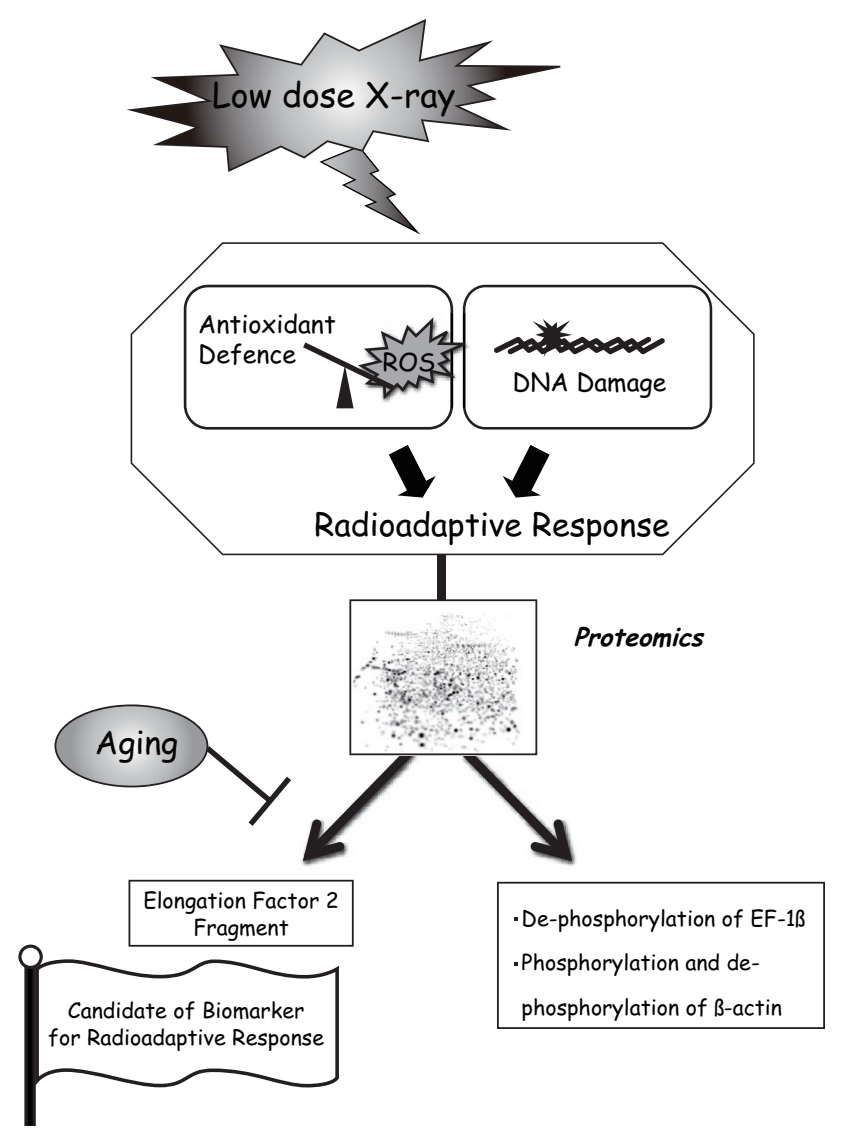

Fig. 3. Schematic illustration of the conclusion of this review

synthesis. In order to identify the EF-2 fragment as the protein responsible for radioadaptive response, further investigation is needed in relation to the generality of the alteration of the EF-2 fragment by low-dose irradiation and the function of the EF-2 fragment in the radiation adaptive response. However, it is expected that the present results will clarify the molecular mechanism of adaptive response and prevent suppression of the adaptive response due to aging, ultimately identifying a biomarker of radioadaptive response.

\section{Conclusion}

We investigated the radioadaptive response to lowdose irradiation and proteomic analysis of the proteins responsible for the radioadaptive response in astrocytes from young and aged rats (Fig. 3). It was suggested that the radioadaptive response in rat astrocytes was suppressed with aging, and that the expression of EF-2 fragment and the phosphorylation of $E F-1 \beta$ and $\beta$-actin varied $3 \mathrm{~h}$ after $0.1 \mathrm{~Gy}$-irradiation. As the temporal increase of the EF-2 fragment was suppressed with aging, while the phosphorylation of $E F-1 \beta$ and $\beta$-actin was not, a possible candidate protein responsible for the radioadaptive response was the EF-2 fragment. The development of research not only for biomarkers of cellular radiation sensitivity, individual radiation susceptibility and gene expression but also for those in radiation oncology and biodefense (e.g. radioadaptive response) may provide new opportunities for healthrelated assessment of radiation-exposed individuals during a long-duration travel in the space (Straume et al. 2008). Although further investigation is needed, it is expected that our present results will ultimately identify biomarker of radioadaptive response and contribute to the development of space medicine.

\section{Acknowledgements}

I would like to thank Dr. Masaki Yamada, Mr. Tsutomu Nishine (Shimadzu Corporation), Ms. Mayumi Kano, Dr. Shozo Suzuki, Dr. Tamao Endo, and Dr. Tosifusa Toda (Tokyo Metropolitan Institute of Gerontology) for technical assistance and advice, and helpful discussion. This work was partly supported by a Grant-in-Aid for Scientific Research (C) (No.20590082) from the Japan Society for the Promotion of Science, and was carried out as a part of the 'Ground-based Research Announcement for Space Utilization' promoted by the Japan Space Forum.

\section{References}

Ahmed, K.M., Nantajit, D., Fan, M., Murley, J.S., Grdina, D.J. and Li, J.J. (2009) Coactivation of atm/ erk/nf-kappab in the low-dose radiation-induced radioadaptive response in human skin keratinocytes, Free Radic. Biol. Med., 46, 1543-1550.

Berglund, S.R., Santana, A.R., Li, D., Rice, R.H., Rocke, D.M. and Goldberg, Z. (2009) Proteomic analysis of low dose arsenic and ionizing radiation exposure on keratinocytes, Proteomics, 9, 1925-1938.

Bolanos, J.P., Heales, S.J., Land, J.M. and Clark, J.B. (1995) Effect of peroxynitrite on the mitochondrial respiratory chain: Differential susceptibility of neurones and astrocytes in primary culture, J. Neurochem., 64, 1965-1972.

de Toledo, S.M., Asaad, N., Venkatachalam, P., Li, L., Howell, R.W., Spitz, D.R. and Azzam, E.I. (2006) Adaptive responses to low-dose/low-dose-rate gamma rays in normal human fibroblasts: The role of growth architecture and oxidative metabolism, Radiat. Res., 166, 849-857.

Filippovich, I.V., Sorokina, N.I., Robillard, N., Lisbona, A. and Chatal, J.F. (1998) Radiation-induced apoptosis in human tumor cell lines: Adaptive response and splitdose effect, Int. J. Cancer, 77, 76-81.

Hiratsuka, M., Inoue, T., Toda, T., Kimura, N., Shirayoshi, Y., Kamitani, H., Watanabe, T., Ohama, E., Tahimic, C.G., Kurimasa, A. and Oshimura, M. (2003) Proteomics-based identification of differentially expressed genes in human gliomas: Down-regulation of sirt2 gene, Biochem. Biophys. Res. Commun., 309, 558-566.

Hollensworth, S.B., Shen, C., Sim, J.E., Spitz, D.R., Wilson, G.L. and LeDoux, S.P. (2000) Glial cell typespecific responses to menadione-induced oxidative stress, Free Radic. Biol. Med., 28, 1161-1174. 
Iyer, R. and Lehnert, B.E. (2002) Low dose, lowlet ionizing radiation-induced radioadaptation and associated early responses in unirradiated cells, Mutat. Res., 503, 1-9.

Korystov, Y.N., Eliseeva, N.A., Kublik, L.N. and Narimanov, A.A. (1996) The effect of low-dose irradiation on proliferation of mammalian cells in vitro, Radiat. Res., 146, 329-332.

Malard, V., Prat, O., Darrouzet, E., Berenguer, F., Sage, N. and Quemeneur, E. (2005) Proteomic analysis of the response of human lung cells to uranium, Proteomics, 5, 4568-4580.

Marples, B. and Joiner, M.C. (1993) The response of chinese hamster v79 cells to low radiation doses: Evidence of enhanced sensitivity of the whole cell population, Radiat. Res., 133, 41-51.

Matsumoto, H., Takahashi, A. and Ohnishi, T. (2004) Radiation-induced adaptive responses and bystander effects, Biol. Sci. Space, 18, 247-254.

Matsumoto, H., Hamada, N., Takahashi, A., Kobayashi, Y. and Ohnishi, T. (2007a) Vanguards of paradigm shift in radiation biology: Radiation-induced adaptive and bystander responses, J. Radiat. Res. (Tokyo), 48, 97106.

Matsumoto, H., Takahashi, A. and Ohnishi, T. (2007b) Nitric oxide radicals choreograph a radioadaptive response, Cancer Res., 67, 8574-8579.

Menard, C., Johann, D., Lowenthal, M., Muanza, T., Sproull, M., Ross, S., Gulley, J., Petricoin, E., Coleman, C.N., Whiteley, G., Liotta, L. and Camphausen, K. (2006) Discovering clinical biomarkers of ionizing radiation exposure with serum proteomic analysis, Cancer Res., 66, 1844-1850.

Mitsumoto, A., Takanezawa, Y., Okawa, K. and Iwamatsu, A., Nakagawa, Y. (2001) Variants of peroxiredoxins expression in response to hydroperoxide stress, Free Radic. Biol. Med., 30, 625-635.

Miura, Y., Abe, K., Urano, S., Furuse, T., Noda, Y., Tatsumi, K. and Suzuki, S. (2002) Adaptive response and the influence of ageing: Effects of low-dose irradiation on cell growth of cultured glial cells, Int. J. Radiat. Biol., 78, 913-921.

Miura, Y. (2004) Oxidative stress, radiation-adaptive responses, and aging, J. Radiat. Res. (Tokyo), 45, 357-372.

Miura, Y., Kano, M., Abe, K., Urano, S., Suzuki, S. and Toda, T. (2005) Age-dependent variations of cell response to oxidative stress: Proteomic approach to protein expression and phosphorylation, Electrophoresis, 26, 2786-2796.

Miura, Y., Kano, M., Yamada, M., Nishine, T., Urano, S., Suzuki, S., Endo, T. and Toda, T. (2007) Proteomic study on $x$-irradiation-responsive proteins and ageing: Search for responsible proteins for radiation adaptive response, J. Biochem., 142, 145-155.

Mohan, N. and Meltz, M.L. (1994) Induction of nuclear factor kappa $b$ after low-dose ionizing radiation involves a reactive oxygen intermediate signaling pathway, Radiat. Res., 140, 97-104.
Nemethova, G., Kalina, I. and Racekova, N. (1995) The adaptive response of peripheral blood lymphocytes to low doses of mutagenic agents in patients with ataxia telangiectasia, Mutat. Res., 348, 101-104.

Noel, F. and Tofilon, P.J. (1998) Astrocytes protect against $\mathrm{x}$-ray-induced neuronal toxicity in vitro, Neuroreport, $\mathbf{9}$, 1133-1137.

Oh-Ishi, M., Ueno, T. and Maeda, T. (2003) Proteomic method detects oxidatively induced protein carbonyls in muscles of a diabetes model otsuka long-evans tokushima fatty (oletf) rat, Free Radic. Biol. Med., 34, 11-22.

Olivieri, G., Bodycote, J. and Wolff, S. (1984) Adaptive response of human lymphocytes to low concentrations of radioactive thymidine, Science, 223, 594-597.

Park, S.H., Lee, Y., Jeong, K., Yoo, S.Y., Cho, C.K. and Lee, Y.S. (1999) Different induction of adaptive response to ionizing radiation in normal and neoplastic cells, Cell Biol. Toxicol., 15, 111-119.

Sasaki, M.S. (1995) On the reaction kinetics of the radioadaptive response in cultured mouse cells, Int. J. Radiat. Biol., 68, 281-291.

Sato, Y., Suzuki, Y., Ito, E., Shimazaki, S., Ishida, M., Yamamoto, T., Yamamoto, H., Toda, T., Suzuki, M., Suzuki, A. and Endo, T. (2006) Identification and characterization of an increased glycoprotein in aging: Age-associated translocation of cathepsin d, Mech. Ageing Dev., 127, 771-778.

Schmidt-Ullrich, R.K., Dent, P., Grant, S., Mikkelsen, R.B. and Valerie, K. (2000) Signal transduction and cellular radiation responses, Radiat. Res., 153, 245-257.

Schoneich, C. (2003) Proteomics in gerontological research, Exp. Gerontol., 38, 473-481.

Shimizu, T., Kato, T., Jr., Tachibana, A. and Sasaki, M.S. (1999) Coordinated regulation of radioadaptive response by protein kinase $c$ and p38 mitogenactivated protein kinase, Exp. Cell Res., 251, 424-432.

Straume, T., Amundson, S.A., Blakely, W.F., Burns, F.J., Chen, A., Dainiak, N., Franklin, S., Leary, J.A., Loftus, D.J., Morgan, W.F., Pellmar, T.C., Stolc, V., Turteltaub, K.W., Vaughan, A.T., Vijayakumar, S. and Wyrobek, A.J. (2008) Nasa radiation biomarker workshop, september 27-28, 2007. Radiat. Res., 170, 393-405.

Suzuki, K., Kodama, S. and Watanabe, M. (1998) Suppressive effect of low-dose preirradiation on genetic instability induced by $x$ rays in normal human embryonic cells, Radiat. Res., 150, 656-662.

Suzuki, K., Kodama, S. and Watanabe, M. (2001) Extremely low-dose ionizing radiation causes activation of mitogen-activated protein kinase pathway and enhances proliferation of normal human diploid cells, Cancer Res., 61, 5396-5401.

Szkanderova, S., Hernychova, L., Kasalova, I., Vavrova, J., Stulik, J., Abend, M. and van Beuningen, D. (2003) Proteomic analysis of radiation-induced alterations in 1929 cells, Folia Biol. (Praha), 49, 15-25.

Takahashi, A. (2002) Pre-irradiation at a low dose-rate blunted p53 response, J. Radiat. Res. (Tokyo), 43, 1-9. 
Takahashi, A., Asakawa, I., Yuki, K., Matsumoto, T., Kumamoto, M., Kondo, N., Ohnishi, K., Tachibana, A. and Ohnishi, T. (2002) Radiation-induced apoptosis in the scid mouse spleen after low dose-rate irradiation, Int. J. Radiat. Biol., 78, 689-693.

Takahashi, A., Matsumoto, H. and Ohnishi, T. (2008) $\mathrm{Hdm} 2$ and nitric oxide radicals contribute to the p53dependent radioadaptive response, Int. J. Radiat. Oncol. Biol. Phys., 71, 550-558.

Tanaka, J., Toku, K., Zhang, B., Ishihara, K., Sakanaka, M. and Maeda, N. (1999) Astrocytes prevent neuronal death induced by reactive oxygen and nitrogen species, Glia, 28, 85-96.

Tapio, S. and Jacob, V. (2007) Radioadaptive response revisited, Radiat. Environ. Biophys., 46, 1-12.

Toda, T., Satoh, M., Sugimoto, M., Goto, M., Furuichi, Y. and Kimura, N. (1998) A comparative analysis of the proteins between the fibroblasts from werner's syndrome patients and age-matched normal individuals using two-dimensional gel electrophoresis, Mech. Ageing Dev., 100, 133-143.

Venkat, S., Chaubey, R.C. and Chauhan, P.S. (1996) Radio-adaptive response in human lymphocytes in vitro, Indian J. Exp. Biol., 34, 909-912.

Wang, B. (2001) Involvement of p53-dependent apoptosis in radiation teratogenesis and in the radioadaptive response in the late organogenesis of mice, J. Radiat . Res. (Tokyo), 42, 1-10.

Wang, T., Tamae, D., LeBon, T., Shively, J.E., Yen, Y., $\mathrm{Li}$, J.J. (2005) The role of peroxiredoxin ii in radiationresistant mcf-7 breast cancer cells, Cancer Res., 65, 10338-10346.

Weissbach, H. and Ochoa, S. (1976) Soluble factors required for eukaryotic protein synthesis, Ann. Rev. Biochem., 45, 191-216.

Wouters, B.G., Sy, A.M. and Skarsgard, L.D. (1996) Lowdose hypersensitivity and increased radioresistance in a panel of human tumor cell lines with different radiosensitivity, Radiat. Res., 146, 399-413. 